\title{
Nicotinic Receptor-Mediated Filtering of Mitral Cell Responses to Olfactory Nerve Inputs Involves the $\alpha 3 \beta 4$ Subtype
}

\author{
Rinaldo D. D'Souza and Sukumar Vijayaraghavan \\ Department of Physiology and Biophysics and Neuroscience Program, University of Colorado School of Medicine, Aurora, Colorado 80045
}

Acetylcholine (ACh) plays a major role in the processing of sensory inputs. Cholinergic input to the mammalian olfactory bulb modulates odor discrimination and perceptual learning by mechanisms that have yet to be elucidated. We have used the mouse olfactory bulb to examine the role of nicotinic ACh receptors ( $\mathrm{nAChRs)}$ in regulating the responses of mitral cells $(\mathrm{MCs})$, the output neurons of the olfactory bulb, to olfactory nerve input. We show that ACh activates $\alpha 3 \beta 4^{\star}$ nAChRs ( ${ }^{\star}$ denotes the possible presence of other subunits) on MCs, leading to their excitation. Despite depolarizing MCs directly, the net effect of nAChR activation is to suppress olfactory nerve-evoked responses in these cells via activity-dependent feedback GABAergic mechanisms. Our results indicate that nAChRs gate incoming olfactory nerve input wherein weak input stimuli are filtered out, whereas strong stimuli are transmitted via the MCs. Based on our observations, we provide a mechanistic model for the sharpening of MC receptive fields by nAChRs, which could aid in odor discrimination and perceptual learning.

\section{Introduction}

Modulation of information processing in the brain by centrifugal projections, such as the axons of cholinergic neurons, forms a significant component of mechanisms involved in learning and memory. Attentional processing of sensory information by $\mathrm{ACh}$ plays a crucial role in the detection and discrimination of inputs (Sarter et al., 2005, 2006). Despite the vast literature documenting cholinergic modulation of behavior, mechanistic insights into how the transmitter might regulate input-output relationships in various brain areas are lacking. These mechanisms are, however, pivotal to our understanding of learning and attentional processes that control various behaviors. nAChRs are key components of cholinergic modulation of these processes (Dani and Bertrand, 2007). A bewildering array of nAChR subtypes and locations, coupled with the high probability of differential, diffusion-based activation (Parikh and Sarter, 2008), suggests multiple roles for these receptors in controlling functions of local circuits.

The olfactory bulb $(\mathrm{OB})$ receives cholinergic input from the horizontal limb of the diagonal band of Broca. Previous behavioral work has suggested an important role for ACh and nAChRs in modulating odor discrimination, odor detection, and olfac-

Received Oct. 3, 2011; revised Jan. 3, 2012; accepted Jan. 20, 2012.

Author contributions: R.D.D. and S.V. designed research; R.D.D. performed research; R.D.D. and S.V. analyzed data; R.D.D. and S.V. wrote the paper.

This work was supported by National Institute on Drug Abuse Grant R01DA10266 and National Institute on Deafness and Other Communication Disorders Grant R01DC008855 (to S.V.). We thank Dr. Nathan Schoppa and Prof. Diego Restrepo for comments and feedback on this manuscript.

Correspondence should be addressed to Sukumar Vijayaraghavan, Department of Physiology and Biophysics, University of Colorado, School of Medicine, MS 8307, P18-7121, 12800, East 19th Avenue, Aurora, C0 80207. E-mail: sukumar.v@ucdenver.edu.

DOI:10.1523/JNEUROSCI.5024-11.2012

Copyright $\odot 2012$ the authors $\quad 0270-6474 / 12 / 323261-06 \$ 15.00 / 0$ tory perceptual learning (Mandairon et al., 2006; Chaudhury et al., 2009; Hellier et al., 2010; Rushforth et al., 2010). However, cellular mechanisms via which $\mathrm{nAChRs} \mathrm{might} \mathrm{modulate} \mathrm{olfactory} \mathrm{learning}$ remain unknown. Current models on $\mathrm{nAChR}$ modulation of the main OB circuit (Linster and Cleland, 2002; Mandairon et al., 2006) are based on a single electrophysiological study that examined the effects of bath application of nicotine and carbachol (Castillo et al., 1999) and previous autoradiographic measurements of nAChR distribution (Le Jeune et al., 1995).

In this brief communication, we examine, for the first time, how nAChRs alter mitral cell (MC) output to inputs from the olfactory nerve $(\mathrm{ON})$. We show that, contrary to predictions from autoradiographic studies (Le Jeune et al., 1995) and observations in the accessory OB (Smith and Araneda, 2010), the major receptor subtype mediating direct excitation of MCs is the $\alpha 3 \beta 4$ subtype of nAChRs. Furthermore, activation of nAChRs results in feedback GABAergic inhibition of the MCs, which gate ON input, allowing only relatively strong inputs to be transmitted to the MCs (Le Jeune et al., 1995). Such a filtering mechanism could potentially reduce overlap of MC responses to an odor, thus sharpening their "receptive fields" (Mandairon et al., 2006). We thus provide a mechanistic model for nAChR effects on OB output.

\section{Materials and Methods}

Animals. Twelve- to 16-d-old FVB/N mice (Charles River), male and female, were used for the experiments described.

Slice preparation and electrophysiology. Horizontal slices $(280 \mu \mathrm{m}$ thick) were prepared from mouse OBs by using a Leica VT1000S vibratome, in ice-cold sucrose-ACSF containing the following (in mM): 72 sucrose, $83 \mathrm{NaCl}, 26 \mathrm{NaHCO}_{3}, 2.5 \mathrm{KCl}, 1 \mathrm{NaH}_{2} \mathrm{PO}_{4}, 20$ glucose, $3 \mathrm{MgCl}_{2}$, and $0.5 \mathrm{CaCl}_{2}$, adjusted to $285-290 \mathrm{mOSm}$. The slices were then allowed to rest in a custom-made chamber containing ACSF at $\sim 32^{\circ} \mathrm{C}$ for $\sim 45$ min before being incubated in the same solution at room temperature 
until recordings. This resting solution had the following substitutions made: $120 \mathrm{~mm} \mathrm{NaCl}$ and no sucrose. Recordings were performed in ACSF containing the following (in $\mathrm{mm}$ ): 1 $\mathrm{MgCl}_{2}$ and $2 \mathrm{CaCl}_{2}$. All solutions were bubbled with $5 \% \mathrm{O}_{2}$ and $95 \% \mathrm{CO}_{2}$. For detection of spontaneous IPSCs (sIPSCs), cells were held at -30 to $-40 \mathrm{mV}$.

Focal pressure application was performed by using a Picospritzer III (Parker Instruments). Pressures were typically $<5$ psi. Electrical stimulation of the ON was performed with a Stimulus Isolator (WPI). Stimulation was most commonly done by placing a glass pipette $(5-10 \mu \mathrm{m}$ tip diameter) filled with extracellular bath solution in the ON layer or $20-80 \mu \mathrm{m}$ superficial to an identified glomerulus.

Data analyses. Because nAChR currents were slow, peak amplitudes were not accurate measures of currents. All nAChR currents are expressed as charge transfer (obtained from the trace integrals) divided by time to allow for comparisons across cells. For analysis of evoked responses in MCs, the electrically evoked EPSCs (eEPSCs) were integrated $>100$ $\mathrm{ms}$ after $\mathrm{ON}$ stimulation to obtain the charge transfer, and this value was divided by 100 . sIPSCs were identified and counted by using AxoGraph X (http://axographx.com/). All combined data are presented as mean \pm SEM. Mean values were compared for statistical significance by using Student's $t$ test on Origin 6.0 software (Microcal). The Kolmogorov-Smirnov (K-S) test was used for comparing distributions for statistical significance by using Mini Analysis (Synaptosoft).

\section{Results}

Functional nAChRs are located on MC glomerular tufts

Bath application of nicotine induces an inward current on MCs, both in the main and accessory $\mathrm{OB}$, suggesting that they have nAChRs (Castillo et al., 1999; Smith and Araneda, 2010). The location of functional nAChRs on MCs is not known. MCs were loaded with $50 \mu \mathrm{M}$ Alexa Fluor 488 in the patch pipette to visualize the primary dendrites and identify glomeruli where they terminated (Fig. 1A). A 1 s application of $1 \mathrm{~mm} A C h$ in the presence of 2 $\mu \mathrm{M}$ atropine (ACh/At; at this concentration atropine blocked $83 \pm 2.3 \%$ of sIPSC increase induced by $100 \mu \mathrm{M}$ oxotremorine; $n=4$ ) at identified glomeruli elicited robust inward currents (Fig. $1 A$; mean $177 \pm 17 \mathrm{pA}$ when cells were held at -70 $\mathrm{mV} ; n=43)$. Application of ACh/At to MC soma (and proximal portions of the secondary dendrites) resulted in much smaller currents (mean $19 \pm 4 \mathrm{pA}, n=20$, $p<0.0001$, unpaired $t$ test) compared with glomerular puffs (Fig. 1C). This $89 \pm$ $2 \%$ reduction in the amplitudes of $\mathrm{nAChR}$ currents suggests that receptors are concentrated on the glomerular tufts of MCs.
A i

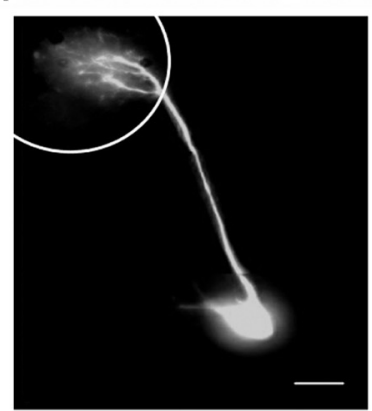

iii

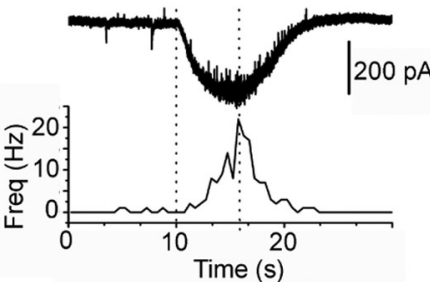

B

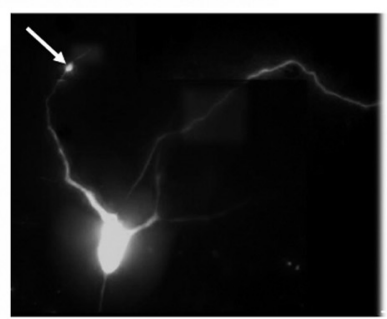

c

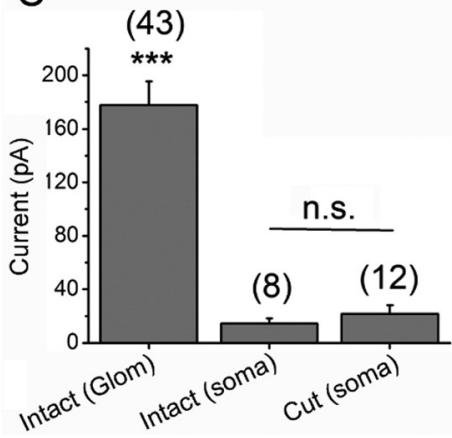

ii

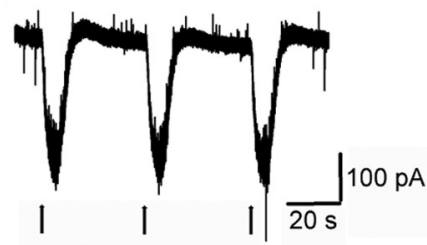

iv

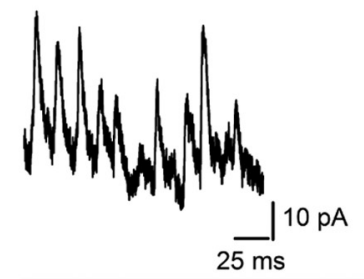

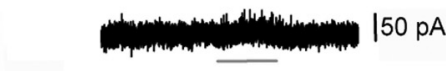
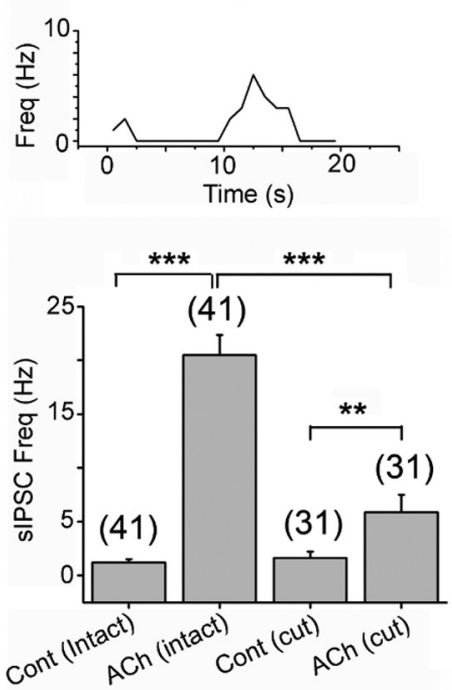

Figure 1. $\mathrm{nAChR}$ effects on MCs. Ai, MCs loaded with $50 \mu \mathrm{m}$ Alexa 488 dextran exhibit an intact primary dendrite that arborizes in a glomerulus. The white circle demarcates the approximate outline of the glomerulus. Scale bar, $20 \mu \mathrm{m}$. Aii, Local application of $1 \mathrm{~mm} \mathrm{ACh/At} \mathrm{(5} \mathrm{s} \mathrm{puffs} \mathrm{start} \mathrm{at} \mathrm{arrows)} \mathrm{in} \mathrm{the} \mathrm{glomerulus} \mathrm{results} \mathrm{in} \mathrm{inward} \mathrm{currents} \mathrm{in} \mathrm{the} \mathrm{MC} \mathrm{shown} \mathrm{in}$ Ai. Holding potential $=-40 \mathrm{mV}$. Aiii, sIPSCs (upward deflections) impinge on the inward currents shown in the trace. Below the trace is shown a frequency plot of the sIPSCs. Dashed lines show the current onset and peak. Aiv, Expanded trace during the ACh/At burst showing individual SIPSCS. B , Left, Another MC exhibits a cut primary dendrite (arrow) but intact lateral dendrites (same scale as in $\mathbf{A i}$ ). Right, Trace shows that local application of $1 \mathrm{~mm} \mathrm{ACh/At} \mathrm{(horizontal} \mathrm{line)} \mathrm{in} \mathrm{the}$ glomerular layer led to a small increase in sIPSC frequency, but resulted in no observable current. The sIPSC frequency plot for the trace shows a small increase in events. C, Left, Focal application of ACh/At onto the MC glomerular tuft induced larger currents than when it was puffed onto the soma $\left({ }^{* * *} p<0.0001\right)$. ACh/At application on the soma of MCs that had an intact primary dendrite did not induce significantly different (n.s.) currents from applications on the soma of MCs without glomerular tufts, thus arguing against diffusion of the agonist. Intact (glom), ACh/At application on glomerula tuft; Intact (soma), application on the soma of MCs with intact primary dendrites; Cut (soma), application on the soma of MCs that lacked a glomerular tuft. Numbers in parentheses are the numbers of cells tested. Right, Intact MCs exhibited a much larger increase in sIPSC frequency than did cut MCs on glomerular ACh/At applications ( $\left.{ }^{* * *} p<0.0001 ;{ }^{* *} p<0.01\right)$. However, MCs with cut primary dendrites did exhibit a small increase in SIPSCs when the agonist was applied at the glomerulus $(p<0.05)$. This small increase in sIPSCs probably arises from downstream activation of granule cells upon MC excitation. Cont, Control (basal sIPSC frequency); ACh, sIPSC frequency upon ACh/At application. 
A

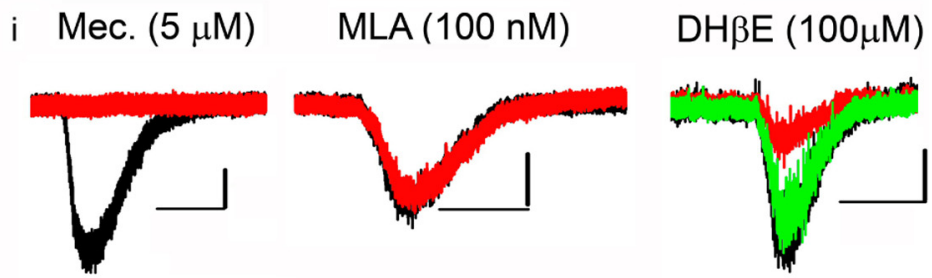

ii $\mathrm{DH} \beta \mathrm{E}(10 \mu \mathrm{M})$
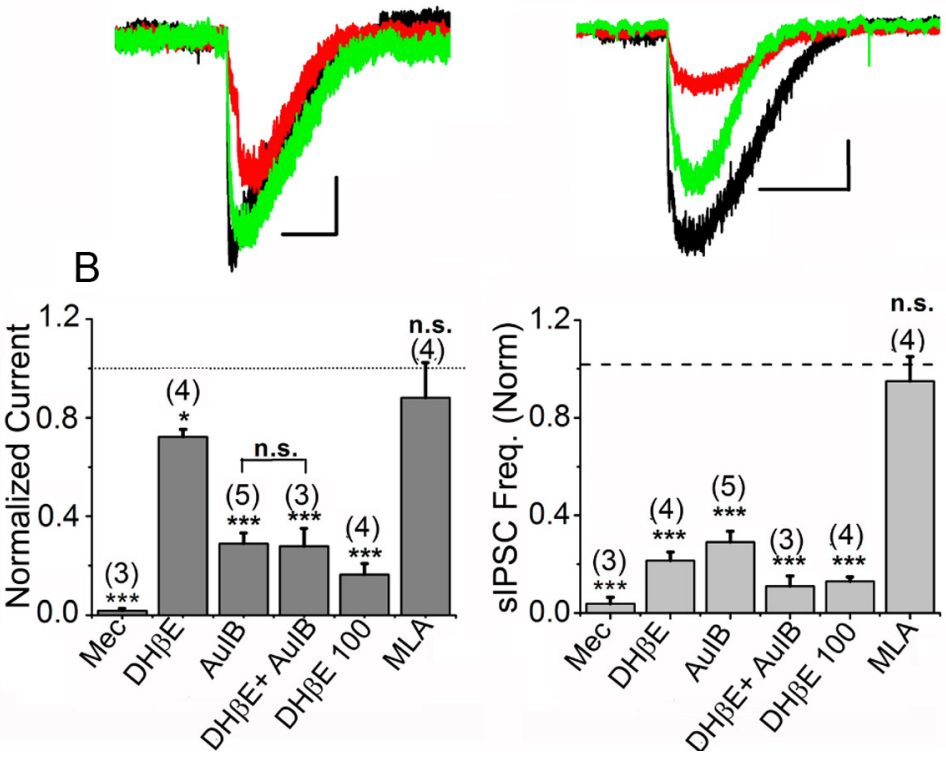

Figure 2. Pharmacology of $n A C h R$ effects. $A$, Representative traces showing control response to ACh/At (black) and response in the presence of $n A C h R$ antagonist (red) and after a $15 \mathrm{~min}$ wash (green). All currents were recorded at $-70 \mathrm{mV}$, and sIPSCs were recorded at $-40 \mathrm{mV}$. Ai, Left, $5 \mu$ m mecamylamine (Mec). Center, 100 nм MLA. Right, $100 \mu$ m DH $\beta$ E. Aii, $10 \mu$ m DH $\beta$ E. Aiii, 10 $\mu м$ CTx-AulB. Among subtype-specific antagonists CTx-AulB was the most effective in suppressing nAChR currents. Scale bars, 100 $\mathrm{pA} / 5$ s. B, Pooled data showing the block of nAChR currents (left) and sIPSC increases (right) by various antagonists. Both DH $\beta E$ and CTx-AulB inhibited the sIPSC increases. The $y$-axis shows responses normalized to control. MLA had no effect on either (n.s.). ${ }^{*} p<$ $0.05{ }^{* * *} p<0.0001$.

Impinging on the nAChR current was a burst of highfrequency sIPSCs (Fig. $1 A$; cells held at $-40 \mathrm{mV}$ to visualize both current and sIPSCs in the same trace). The sIPSC frequencies increased from a basal $1.2 \pm 0.3$ to $20.5 \pm 1.9 \mathrm{~Hz}$ in the presence of the agonist ( $n=41, p<0.0001$, paired $t$ test). Because of the slicing procedure, some MCs lacked a glomerular tuft, but exhibited intact lateral dendrites (Fig. 1 B). Such "cut" MCs exhibited a small, but significant, increase in sIPSC frequency upon $1 \mathrm{~s}$ local applications of ACh/At in the glomerular layer (Fig. $1 B, C$; $p<$ $0.01, n=31$ ). These findings are consistent with a large fraction of sIPSCs being derived from GABA release in the glomerulus by periglomerular cells. sIPSCs were reversibly abolished by $10 \mu \mathrm{M}$ gabazine ( $\mathrm{GBz} ; n=4)$, thus confirming the sIPSCs to be GABAergic currents.

Incubating slices with the GluR blockers [D-AP5, $100 \mu \mathrm{M}$; DNQX, $50 \mu \mathrm{M}$; and $(R S)$ - $\alpha$-methyl-4-carboxyphenylglycine, 1 $\mathrm{mm}$ ] attenuated sIPSC frequency increases on MCs $(88 \pm 3 \%$ inhibition, $n=3, p<0.03$ ). This indicates that a primary trigger for increased GABA release in the glomerulus is the excitation of MCs and/or external tufted (ET) cells. Recent studies have provided evidence for a glutamatergic feed-forward excitation of MCs by ET cells (De Saint Jan et al., 2009). We therefore tested whether the large nAChR currents in MCs had a glutamatergic component. The mixture of GluR blockers did not alter the current $(n=4, p=$ 0.92 , paired $t$ test, with and without blockers), nor were the currents blocked by tetrodotoxin ( $1 \mu \mathrm{M} ; n=4, p=0.44)$. These results suggest that, unlike sIPSC changes, MCs are directly activated by nAChRs, rather than via secondary glutamatergic mechanisms.

\section{Pharmacology of nAChR effects on MCs}

Both the nAChR currents and sIPSC increases in MCs were abolished by $5 \mu \mathrm{M}$ mecamylamine (Fig. $2 A i, B$ ). In the presence of this general $n A C h R$ antagonist (although not very effective at $\alpha 7$-containing nAChRs at this concentration), the currents were inhibited by $96 \pm 2 \%(n=3$, $p<0.002)$, and the increases in sIPSC frequency were inhibited by $93 \pm 6.5 \%(n=$ $3, p<0.002$, unpaired $t$ tests), compared with control values. Treating cells with $100 \mathrm{~nm}$ methyllycaconitine (MLA), an antagonist of the $\alpha 7$-containing nAChR, did not affect either the currents $(n=4, p=$ 0.31 , paired $t$ test) or the increase in sIPSC frequencies ( $n=4, p=0.63$, paired $t$ test) (Fig. 2Aiii,B). Our results suggest that the glomerular nicotinic effects we observed are mediated by non- $\alpha 7$-containing heteromeric nAChRs.

Dihydro- $\beta$-erythroidine (DH $\beta$ E) $(100$ $\mu \mathrm{M})$, at concentrations not selective for $\alpha 4 \beta 2$-containing nAChRs, reversibly inhibited ACh-mediated currents (88.9\% block; $n=5, p<0.0001$; recovered to $45.9 \%$ of control after a 15 min wash, $p<$ $0.0001)$. At a more selective concentration, $\mathrm{DH} \beta \mathrm{E}(10 \mu \mathrm{M})$ resulted in only a small decrease in current amplitudes (20 $\pm 7 \%$ block, $n=4, p<$ 0.05 ) (Fig. $2 A i i, B)$, suggesting either a small contribution from $\alpha 4 \beta 2^{\star} \mathrm{nAChRs}$ or simply a lower-affinity interaction of the drug with other nAChRs. On the other hand, incubating slices with 10 $\mu \mathrm{M}$ conotoxin AuIB (CTx-AuIB), specific for the $\alpha 3 \beta 4$ containing subtype (Luo et al., 1998), attenuated ACh/Atinduced MC currents by $71 \pm 4.4 \%(n=5, p<0.0001)$ (which recovered to $53.7 \%, n=5, p<0.01$ ) (Fig. $2 A i v, B$ ). In the presence of both inhibitors $(n=4)$, there was no additional attenuation of the currents $(p=0.57)$. These results suggest that a dominant subtype generating MC currents is the $\alpha 3 \beta 4^{\star} \mathrm{nAChR}$. Both Ctx-AuIB $(10 \mu \mathrm{M})$ and $\mathrm{DH} \beta \mathrm{E}(10 \mu \mathrm{M})$ inhibited AChmediated sIPSC frequency increases on MCs (Fig. $2 B ; n=5$ for CTx-AuIB and $n=4$ for DH $\beta E, p<0.001$ for both), implying that $\alpha 4 \beta 2^{*}$ nAChRs might play a role in modulating GABA release on to the MCs as well. In $3 / 5$ cells treated with Ctx$\mathrm{AuIB}$, the sIPSC frequencies recovered to $73 \pm 6 \%$ of control upon washout.

\section{nAChR-mediated GABA release attenuates $\mathrm{MC}$ responses to ON-evoked signals}

How does $\mathrm{nAChR}$ activation alter MC excitation to odor input? To mimic the effects of odor input from sensory neurons and 
examine the nAChR modulation of glomerular output, we electrically stimulated the ON layer and measured eEPSCs in MCs (Fig. 3Ai). The eEPSCs were entirely glutamatergic in nature. In the presence of $50 \mu \mathrm{M}$ DNQX and $100 \mu \mathrm{M} \mathrm{APV}$, all currents were abolished $(n=3, p<0.001)$ and recovered to $75.9 \%$ of control upon wash $(p<0.001)$. When the olfactory nerve was stimulated during the slow nAChR current, the eEPSCs were significantly smaller than during control conditions (Fig. 3Aii, top traces; $n=14, p<$ 0.0001 , K-S test), which were reversed with GABA receptor blockers (Fig. 3Aii, bottom traces).

The distribution of eEPSC amplitudes during the nAChR current significantly shifted toward smaller values. This was true for all stimulus intensities tested (Fig. $3 B, C)$. The suppression resulted in abolishment of eEPSCs from weak stimulus intensities but measurable responses from stronger ones (Fig. $3 B, C$ ). We confirmed that the leftward shift in eEPSC amplitude distribution was caused by increased GABA release upon nAChR activation by applying GABA receptor blockers to the bath solution (Fig. 3C). In the presence of $10 \mu \mathrm{M} \mathrm{GBz}$ alone, the nAChR-mediated leftward shift in the eEPSC amplitude distribution was abolished $(n=3, p>0.4$, $\mathrm{K}-\mathrm{S}$ test). Adding $10 \mu \mathrm{M} \mathrm{GBz}+1 \mu \mathrm{M}$ CGP-54626 to block both GABA receptor classes resulted in a rightward shift of the amplitude distribution compared with control conditions (Fig. $3 C ; n=5, p<$ 0.03 , K-S test) and compared with GBz alone $(p<0.002)$. These results suggest that the effects of nAChR-mediated inhibition might arise from $\mathrm{GABA}_{\mathrm{A}}$ as well as $\mathrm{GABA}_{\mathrm{B}}$ receptor activation.

These results suggest that, despite MC excitation, the net effect of nAChR activation is to suppress MC activation by $\mathrm{ON}$ inputs.

\section{nAChRs gate $\mathrm{ON}$ inputs}

Can the nAChR-mediated inhibition of MC eEPSCs act as a filter for incoming ON inputs? To test this, we examined the effects of $\mathrm{nAChR}$ activation on $\mathrm{MC}$ responses to $\mathrm{ON}$ excitation, under current clamp configuration, while varying the intensity levels of $\mathrm{ON}$ stimulation. We measured the net increase in AP spikes upon ON stimulation, under control conditions, as well as during the $\mathrm{ACh} /$ At-induced depolarization (Fig. 4Ai-Aiv). The depolarization induced by ACh/At application, by itself, caused the cells to pass threshold and fire APs. Under control conditions, the cells responded with multiple spikes upon ON stimulation under the range of stimulus conditions used. However, both failures as well as high-frequency responses were detected in the presence of ACh/At (Fig. 4Ai-D).

The net increase in AP spikes was measured by subtracting the frequency of spikes before $\mathrm{ON}$ stimulation $(0 \mathrm{~Hz}$ under control conditions in all cases and, on average, $19.03 \pm 1.90 \mathrm{~Hz}$ with
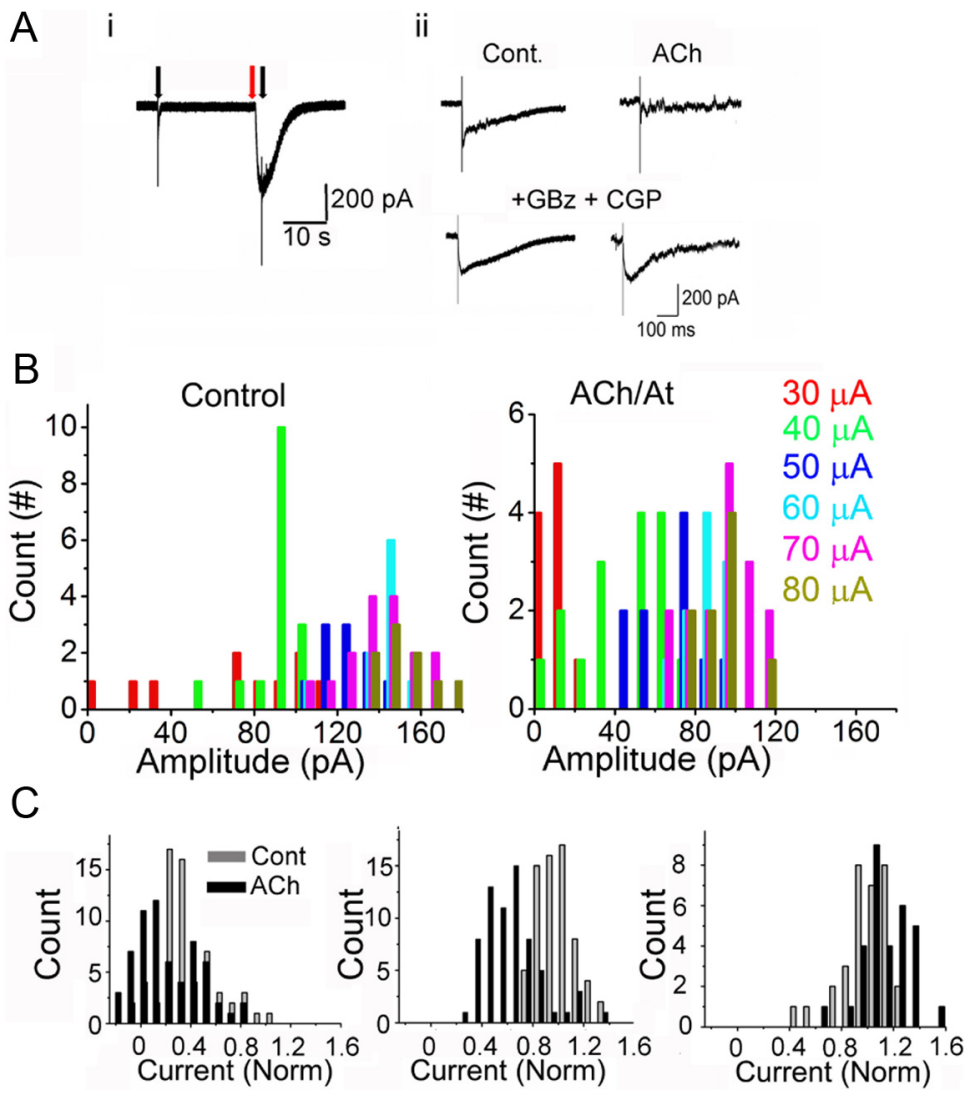

Figure 3. $n A C h R$ activation suppresses $0 \mathrm{~N}$-evoked responses in $M C s$. Ai, Voltage-clamp recording from a representative $M C$ The $\mathrm{ON}$ was electrically stimulated at the two black arrows. A $1 \mathrm{~s}, 1 \mathrm{~mm}$ ACh/At puff was focally applied at the red arrow. Aii, Top , Expanded trace of the ON-evoked EPSC from Ai under control conditions. Right, During the ACh/At-induced current, the cell as in $\mathbf{A i}$, in the presence of the GABA receptor blockers. Right, In the presence of the GABA receptor blockers, during the ACh-induced current, the nAChR-mediated suppression of eEPSCs is abolished. $\boldsymbol{B}$, Left, Data from a single MC showing eEPSC elicited by $0 \mathrm{~N}$ stimulation at various intensities $(30-80 \mu \mathrm{A})$. Right, The same cell shows suppression of all $0 \mathrm{~N}$ responses when elicited during the ACh/At-induced currents. C, Left, Amplitude histogram showing a leftward shift of eEPSC amplitude distribu.0001). Center, Similar leftward shift is observed for high ON stimulation intensities. eEPSC values in the left and center panels $\mathrm{GBz}+1 \mu \mathrm{M}$ CGP-54626, the leftward shift of the eEPSC distribution was abolished (black) and was significantly shifted to the right of the control distribution (gray; $n=5, p<0.03, \mathrm{~K}-\mathrm{S}$ test).

$\mathrm{ACh} / \mathrm{At} ; n=7$ ) from the frequency within $100 \mathrm{~ms}$ after ON stimulation. Data from a representative cell (Fig. 4C) show that in the presence of $\mathrm{ACh} / \mathrm{At}$ the firing rate was decreased at all stimulus intensities, resulting in failures at lower intensities. The results were reproduced in seven cells (Fig. $4 D$ for compiled data).

Directly depolarizing the MC in current clamp to mimic the ACh-mediated depolarization did not lead to filtering of MC responses (representative traces in Fig. $4 E$ ), suggesting that filtering of olfactory nerve input requires the activation of multiple neurons that are part of the glomerular circuit. Mean frequency of ON-evoked APs in the presence of ACh/At was $5.23 \pm 1.73 \mathrm{~Hz}$; for the same intensities, the mean frequency during a depolarizing ramp (in the absence of any agonist) was $36.5 \pm 1.35 \mathrm{~Hz}(n=$ $4, p<0.001)$.

For each cell tested, we pooled the effects of ON stimulation for the lowest and highest stimulation intensities that evoked a spiking response under control conditions. In both cases, stimulating the $\mathrm{ON}$ during the $\mathrm{ACh} / \mathrm{At}$-induced depolarization decreased the net MC spike response compared with control ( $n=7$, $p<0.0001$ for both high and low intensities) (Fig. 4D). This 
$\mathrm{Ai}$ $40 \mu \mathrm{A}$

Aii

$50 \mu \mathrm{A}$
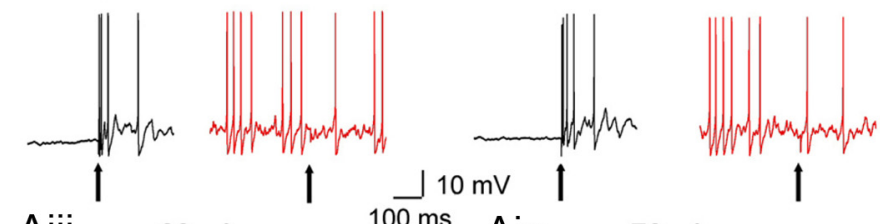

Aiii $60 \mu \mathrm{A}$

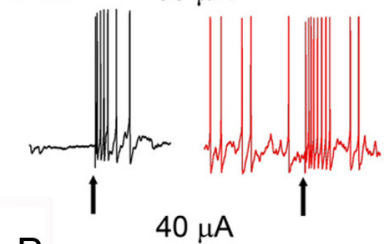

B

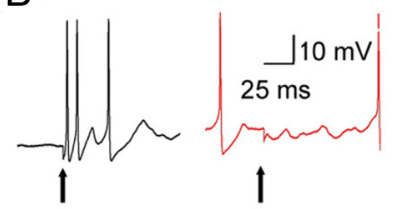

C

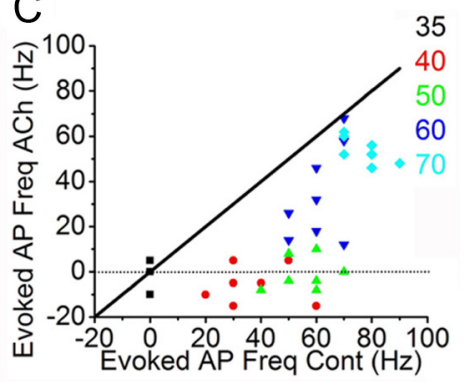

E $\quad \mathrm{ACh} / \mathrm{At}$

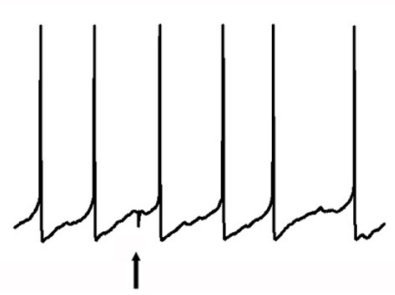

Aiv

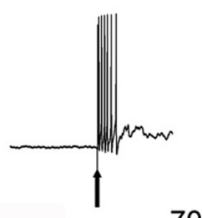

$70 \mu \mathrm{A}$

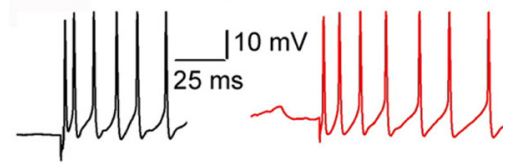

1

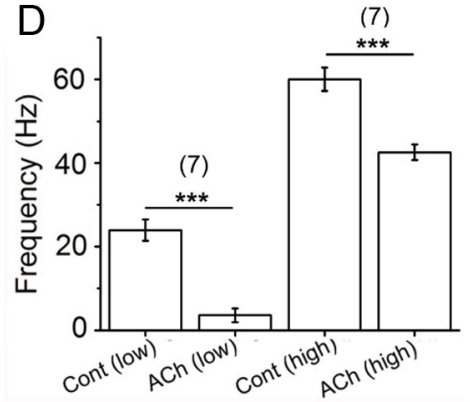

Ramp

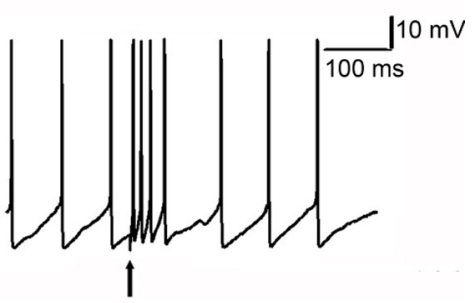

Figure 4. Nicotinic filtering of weak $0 \mathrm{~N}$ inputs. Ai, Same experimental setup as in Figure $3 A$, but under current clamp. Left, A 40 $\mu \mathrm{A} O \mathrm{~N}$ stimulus causes an MC to exhibit a burst of spikes. Right, During the ACh/At-mediated depolarization (and enhanced background firing), the $40 \mu$ A stimulus fails to evoke a response in the same MC. Aii-Aiv, Similar data for 50 (Aii), 60 (Aiii), and 70 (Aiv) $\mu \mathrm{A}$ stimuli. Whereas the $50 \mu \mathrm{A}$ stimulus also fails to evoke a response during the ACh/At-mediated spiking in the same $M C$ as in $\boldsymbol{A i}$, the $M C$ responds to higher stimuli with increased spiking. In all cases, control traces are in black, and traces in the presence of ACh/At are in red. $\boldsymbol{B}$, Expanded traces from Ai and Aiv. C, Scatter plot of net increase in spiking upon ON stimulation,

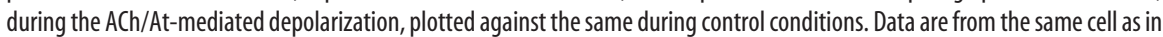
$\boldsymbol{A} \boldsymbol{i}-$ Aiv and $\boldsymbol{B}$. Numbers indicate stimulus intensities in microamps. Whereas responses to all stimulus intensities were suppressed during the $A C h$-mediated depolarization, lower intensity stimuli (up to $50 \mu \mathrm{A}$ ) show a filtering of $\mathrm{MC}$ responses (not different from 0). Diagonal line (slope $=1$ ) shows an arbitrary line where the points would lie if there was no ACh-mediated filtering. $\boldsymbol{D}$, Pooled data from seven MCs for the lowest intensity that exhibited an $0 \mathrm{~N}$-evoked response under control conditions and the highest stimulus intensity. At both intensities the net firing frequency was reduced upon nAChR activation ( ${ }^{* * *} p<0.0001$ ). For low intensities, stimulating the $0 \mathrm{~N}$ during the $\mathrm{ACh} / \mathrm{At}$-induced depolarization ( $\mathrm{ACh}$ low) did not evoke a significant increase in MC firing $(p=0.76$, not significant from 0$)$, thus suggesting a filtering mechanism. E, Filtering shown in the presence of ACh/At (left) is not seen when the same cell is depolarized to elicit APs in the absence of ACh/At (right; Ramp, from the same cell). The same stimulus intensities were used for both conditions.

decrease in response results in filtering out of responses to weaker stimuli ( $p=0.76$, not different from 0 ), while allowing stronger ones to be detected.

\section{Discussion}

In this brief communication, we demonstrate that MCs are directly excited by nAChRs. This excitation, coupled with feedback

inhibition from presumably the inhibitory periglomerular and/or granule cells, controls the response of MCs to ON inputdriven stimuli. ON inputs that impinge on MCs during the period of $\mathrm{AAChR}$ activation are suppressed by the GABA-mediated feedback response, leading to a filtering of weak input. This study provides a mechanism to explain nAChR effects on odor discrimination and olfactory perceptual learning reported in the literature (Hellier et al., 2010; Rushforth et al., 2010). Our results, in conjunction with previous studies examining the role of muscarinic receptor modulation of MC-to-granule cell signaling (Castillo et al., 1999; Ghatpande et al., 2006; Pressler et al., 2007; Ghatpande and Gelperin, 2009), provide deeper insights into the cholinergic control of olfaction.

The unexpected role for $\alpha 3 \beta 4^{\star}$ nAChRs in $\mathrm{MC}$ excitation is counter to predictions made from autoradiographic measurements (Le Jeune et al., 1995). Previously not thought to have an important role in CNS functions, this subtype of receptors is gaining recognition as an important mediator of nicotine actions in the brain (Salas et al., 2004; Mineur et al., 2011). In the $\mathrm{OB}, \alpha 3$ and $\beta 4$ mRNAs have been shown to be present in MCs and the accessory OB (Keiger and Walker, 2000; Salas et al., 2004).

We used two previous findings in the field as a basis for a functional model for nAChR modulation. First, ACh levels are very low in the slow-wave sleep state and rise significantly in a tonic fashion upon arousal (Parikh et al., 2007). During behavior, at the attentional/anticipation phase, there is an abrupt and large phasic increase in ACh levels (Parikh et al., 2007). The second set of findings comes from MC recordings in awake behaving animals. MCs are silent in anesthetized animals but tonically fire during the awake state. It has been speculated that the basal level of MC firing might be driven by ACh levels during general arousal. Further, there is an increased firing of MCs in the attentional/anticipation phase just before odor detection, consistent with studies described above showing a phasic spike in ACh levels. In addition, individual MCs in awake behaving animals respond to odors less commonly than in the anesthetized state, presumably because of a lack of filtering mechanisms in the anesthetized state (Rinberg et al., 2006).

During the attentional phase, the rapid spike in ACh levels would be sufficient to activate nAChRs, especially the heteromeric, non- $\alpha 7$-containing nAChRs. Such an increase would result in increased MC firing that might set up a template upon which odorant signals impinge. Although the information car- 
ried by this template is yet unknown, the increased firing might serve to set detection thresholds and act as a filter for incoming odor inputs wherein small increases in spike frequency upon ON stimulation might not be detected over the basal firing. Although counterintuitive, the increase in MC spiking by $\mathrm{nAChR}$ activation could therefore act to decrease noise in the OB circuit by suppressing weak $\mathrm{ON}$ inputs. In addition, this template makes it possible for MCs to be inhibited by odor onset (such as via lateral inhibition), thus increasing possible coding mechanisms.

We hypothesize that nicotinic filtering of weak inputs could decrease overlap of MC responses to odors, thus sharpening the molecular receptive fields of individual MCs, which could potentially lead to improved odor discrimination and perceptual learning (Mandairon et al., 2006).

\section{References}

Castillo PE, Carleton A, Vincent JD, Lledo PM (1999) Multiple and opposing roles of cholinergic transmission in the main olfactory bulb. J Neurosci 19:9180-9191.

Chaudhury D, Escanilla O, Linster C (2009) Bulbar acetylcholine enhances neural and perceptual odor discrimination. J Neurosci 29:52-60.

Dani JA, Bertrand D (2007) Nicotinic acetylcholine receptors and nicotinic cholinergic mechanisms of the central nervous system. Annu Rev Pharmacol Toxicol 47:699-729.

De Saint Jan D, Hirnet D, Westbrook GL, Charpak S (2009) External tufted cells drive the output of olfactory bulb glomeruli. J Neurosci 29:20432052.

Ghatpande AS, Gelperin A (2009) Presynaptic muscarinic receptors enhance glutamate release at the mitral/tufted to granule cell dendrodendritic synapse in the rat main olfactory bulb. J Neurophysiol 101:20522061.

Ghatpande AS, Sivaraaman K, Vijayaraghavan S (2006) Store calcium mediates cholinergic effects on mIPSCs in the rat main olfactory bulb. J Neurophysiol 95:1345-1355.

Hellier JL, Arevalo NL, Blatner MJ, Dang AK, Clevenger AC, Adams CE, Restrepo D (2010) Olfactory discrimination varies in mice with different levels of $\alpha 7$-nicotinic acetylcholine receptor expression. Brain Res 1358:140-150.

Keiger CJ, Walker JC (2000) Individual variation in the expression profiles of nicotinic receptors in the olfactory bulb and trigeminal ganglion and identification of $\alpha 2, \alpha 6, \alpha 9$, and $\beta 3$ transcripts. Biochem Pharmacol 59:233-240.
Le Jeune H, Aubert I, Jourdan F, Quirion R (1995) Comparative laminar distribution of various autoradiographic cholinergic markers in adult rat main olfactory bulb. J Chem Neuroanat 9:99-112.

Linster C, Cleland TA (2002) Cholinergic modulation of sensory representations in the olfactory bulb. Neural Netw 15:709-717.

Luo S, Kulak JM, Cartier GE, Jacobsen RB, Yoshikami D, Olivera BM, McIntosh JM (1998) $\alpha$-Conotoxin AuIB selectively blocks $\alpha 3 \beta 4$ nicotinic acetylcholine receptors and nicotine-evoked norepinephrine release. J Neurosci 18:8571-8579.

Mandairon N, Ferretti CJ, Stack CM, Rubin DB, Cleland TA, Linster C (2006) Cholinergic modulation in the olfactory bulb influences spontaneous olfactory discrimination in adult rats. Eur J Neurosci 24:32343244.

Mineur YS, Abizaid A, Rao Y, Salas R, DiLeone RJ, Gündisch D, Diano S, De Biasi M, Horvath TL, Gao XB, Picciotto MR (2011) Nicotine decreases food intake through activation of POMC neurons. Science 332:13301332.

Parikh V, Sarter M (2008) Cholinergic mediation of attention: contributions of phasic and tonic increases in prefrontal cholinergic activity. Ann N Y Acad Sci 1129:225-235.

Parikh V, Kozak R, Martinez V, Sarter M (2007) Prefrontal acetylcholine release controls cue detection on multiple timescales. Neuron 56:141154.

Pressler RT, Inoue T, Strowbridge BW (2007) Muscarinic receptor activation modulates granule cell excitability and potentiates inhibition onto mitral cells in the rat olfactory bulb. J Neurosci 27:10969-10981.

Rinberg D, Koulakov A, Gelperin A (2006) Sparse odor coding in awake behaving mice. J Neurosci 26:8857-8865.

Rushforth SL, Allison C, Wonnacott S, Shoaib M (2010) Subtype-selective nicotinic agonists enhance olfactory working memory in normal rats: a novel use of the odour span task. Neurosci Lett 471:114-118.

Salas R, Cook KD, Bassetto L, De Biasi M (2004) The $\alpha 3$ and $\beta 4$ nicotinic acetylcholine receptor subunits are necessary for nicotine-induced seizures and hypolocomotion in mice. Neuropharmacology 47:401-407.

Sarter M, Hasselmo ME, Bruno JP, Givens B (2005) Unraveling the attentional functions of cortical cholinergic inputs: interactions between signal-driven and cognitive modulation of signal detection. Brain Res Brain Res Rev 48:98-111.

Sarter M, Gehring WJ, Kozak R (2006) More attention must be paid: the neurobiology of attentional effort. Brain Res Rev 51:145-160.

Smith RS, Araneda RC (2010) Cholinergic modulation of neuronal excitability in the accessory olfactory bulb. J Neurophysiol 104:2963-2974. 